\title{
Plastinación, una Herramienta Adicional para la Enseñanza de la Anatomía
}

\author{
Plastination an Additional Tool to Teach Anatomy \\ Hermes Bravo
}

BRAVO, H. Plastinación, una herramienta adicional para la enseñanza de la Anatomía. Int. J. Morphol., 24(3):475-480, 2006.

RESUMEN: En nuestro Departamento de Anatomía de la Escuela de Medicina hemos implementado un laboratorio de plastinación, con el fin de aprovechar eficientemente el material cadavérico disponible. Para tal efecto, utilizamos polímeros de silicona que se trabajan a temperatura ambiente. Esto nos ha permitido maximizar los procesos de producción de plastinados. De hecho, en los tres años de funcionamiento de nuestro laboratorio, hemos realizado 300 plastinados en silicona y 85 en resina poliéster. Todos ellos han sido incorporados a la docencia de los cursos de pregrado de Anatomía y Neuroanatomía para Medicina, de Anatomía para Enfermería y a los cursos de postítulo para los Becados de Neurología - Neurocirugía, de Radiología, de Anestesiología y de Otorrinolaringología. Esto ha significado que además, de las disecciones tradicionales, los alumnos puedan contar con un número significativamente mayor de preparados anatómicos disponibles en los pasos prácticos, situación muy apreciada por ellos, dado que están concientes de disponer de este material es muy importante en el aprendizaje de la anatomía del cuerpo humano.

PALABRAS CLAVE: Plastinación; Silicona; Resina poliéster.

\section{INTRODUCCIÓN}

En la enseñanza de la Anatomía, el uso de preparaciones cadavéricas sigue siendo el método mas eficiente para lograr que el estudiante comprenda y retenga por más tiempo el conocimiento que le será útil en su ejercicio profesional futuro (Bravo \& Inzunza 1995, Inzunza \& Bravo 1999). Como la disponibilidad de material cadavérico es cada día más difícil, hemos decidido implementar un laboratorio de plastinación en el Departamento de Anatomía de la Escuela de Medicina de la Pontificia Universidad Católica de Chile. Esta técnica permite preservar el material cadavérico sustituyendo el agua y grasa de los preparados por un polímero como la silicona o la resina poliéster (von Hagens et al., 1987). Este método nos ha permitido disponer y utilizar todo el material de preparados para la docencia, sin tener que descartar piezas que se deterioran con el transcurso de los años cuando son mantenidas con técnicas convencionales.

\section{MATERIAL Y MÉTODO}

En los últimos años, he probado diferentes polímeros y métodos de plastinación; esta experiencia me permite aseverar que la elección adecuada del tipo de silicona y la técnica a seguir es fundamental para hacer más eficiente la línea de producción de plastinados, clave que es válida tanto para la silicona como para las resinas, sean éstas poliéster o epóxica.

En el mercado existen siliconas que deben trabajarse a $-20^{\circ} \mathrm{C}$, mientras que otras pueden trabajarse a temperatura ambiente. He seleccionado estas últimas, ya que ello me permite procesar indistintamente preparados que van a impregnarse en silicona como en resina poliéster, material que también debe trabajarse a temperatura ambiente. El equipamiento que un laboratorio de plastinación necesita es: un feezer ($20^{\circ} \mathrm{C}$ ), cuyo tamaño depende de los preparados que se pretende realizar; una bomba, que permita lograr vacíos de hasta 15 milibares, un contenedor hermético, de acero, que soporte el vacío antes mencionado, conectado a una campana de extracción de flujo laminar.

Plastinados en Silicona. La silicona es un polímero que proporciona preparados opacos con consistencia de goma rígida. Por lo tanto, son recomendados para disecciones bien ejecutadas, preparaciones que muestren las estructuras que se quiere destacar en primer plano (Fig. 6) o en niveles diferentes y que puedan ser removidas como un modelo desarmable (Fig.7). 
La fijación ideal para estos preparados debe contener formalina, en concentraciones no mas allá de $5 \%$, por períodos en lo posible cortos, (una a dos semanas), para evitar el oscurecimiento de la muestra. Sin embargo, si se tienen preparaciones muy antiguas, también pueden ser plastinadas, previo a blanqueamiento de ellas en agua oxigenada.

El proceso de deshidratación se realiza con acetonas de $70 \%, 80 \%, 90 \%$ y $100 \%$, a una temperatura de $-20^{\circ} \mathrm{C}$, para evitar la contracción o encogimiento de los tejidos, fenómeno que se maximiza si la deshidratación se efectúa a temperatura ambiente. El tiempo de deshidratación y extracción de lípidos en cada acetona, depende del tamaño de la preparación, nuestros rangos van entre 3 y 7 días. Es recomendable enfriar previamente a $4^{\circ} \mathrm{C}$, la preparación, antes de introducirla en la primera acetona ya que ésta se encuentra a muy baja temperatura. Para precisar el grado de deshidratación del tejido se utiliza un acetómetro, instrumento que mide la cantidad de agua que contiene la acetona, por lo tanto, permite inferir cuanta agua se ha extraído de la preparación. Para ello, se mide la acetona antes de poner la preparación y después de retirar ésta. Cuando la lectura del acetómetro indica una cantidad de aproximadamente 2 a $3 \%$ de agua, se está en condiciones de pasar al siguiente paso, que es la impregnación forzada en vacío. Este procedimiento se realiza a temperatura ambiente. La resina ( importada desde U.S.A., Corcoran Laboratories) se prepara en la siguiente proporción: por cada $100 \mathrm{ml}$ de Silicona PR10 se agregan $5 \mathrm{ml}$ de crosslinker CR-22. Una vez realizada esta mezcla se puede reutilizar muchas veces debido a que requiere del catalizador para polimerizar. La pieza anatómica que se ha retirado de la última acetona, se deja estilar unos minutos a temperatura ambiente, para luego sumergirla en la mezcla antes mencionada y colocarla en la cámara de vacío, de modo de obtener un burbujeo constante y suave, hecho que indica que la acetona está siendo retirada del tejido y está siendo reemplazada por el polímero. En la medida que pasa el tiempo, se va incrementando el vacío hasta llegar a 15 milibares. Para una preparación grande el proceso de impregnación puede tomar varias horas. Una vez que la silicona deja de burbujear, la preparación se retira de la cámara de vacío, se deja estilar por una media hora, para luego agregar una delgada capa de catalizador CT-32. Esta aplicación se puede realizar con una brocha pequeña o con un pulverizador. Luego la preparación se guarda por 24 horas en un contenedor cerrado, siendo útil para ello una bolsa plástica sellada o un recipiente de vidrio herméticamente cerrado.

Al día siguiente, se retira y se limpia el exceso de catalizador, colocando la preparación en un ambiente con alta humedad por varios días. Si se desea acelerar el proceso de fraguado, se puede incrementar la cantidad de crosslinker en la mezcla inicial o sumergir la pieza en agua tibia.
Para obtener colores más naturales, especialmente en los músculos, es posible teñirlos con un colorante (AC10, Corcoran Laboratories) preparado al $1 \%$ en acetona al $80 \%$ (Fig. 1).

Plastinados en resina poliéster. La resina poliéster es un polímero que se puede obtener en el mercado nacional. Este material proporciona preparados que tienden a diafanizarse, apreciándose en ellos varios planos, cuando son observados con minuciosidad. Las preparaciones son rígidas y fáciles de fracturar. Esta técnica es recomendada para cortes de diferentes segmentos corporales (Fig.3).

La fijación para este caso, es igual a la descrita para silicona.

En la deshidratación, he realizado dos variantes. Una que utiliza acetonas de $70 \%, 80 \%, 90 \%$ y $100 \%$, a temperatura de $-20^{\circ} \mathrm{C}$, que permite obtener preparaciones que se transparentan después de la impregnación forzada. La otra variante utiliza alcoholes de 70\%, 80\%, 90\% y 100\%, a temperatura ambiente, para luego incluir la preparación sin realizar una impregnación forzada. Esta última técnica, que es un nuevo aporte de nuestro laboratorio, ha sido muy útil para incluir en resina poliéster, cortes de cerebro que han sido teñidos previamente con el método de Barnard et al. (1949). Esta variante da preparaciones opacas. (Fig. 5).

En la impregnación forzada de la primera variante, se utiliza resina poliéster nacional P-40, en la siguiente proporción: por cada $100 \mathrm{ml}$ de resina se agregan 50 microlitros de cobalto y 150 microlitros de catalizador.

La preparación se retira de la última acetona, se estila, se sumerge en la mezcla mencionada utilizando para ello un molde de vidrio, colocando un peso sobre la preparación para evitar que flote. Luego, se lleva a la cámara de vacío a temperatura ambiente. Al igual que lo descrito para la técnica de silicona, el vacío debe generar un burbujeo constante y suave, lo que indica que la acetona está siendo retirada del tejido y está siendo reemplazada por la resina. En la medida que pasa el tiempo se va incrementando el vacío sin sobrepasar los 15 milibares, ya que un vacío mayor extrae componentes químicos de la resina que desnaturalizan el aceite de la bomba de vacío. Una vez que ha terminado la impregnación, se lleva el molde de vidrio a la campana de extracción, lugar en el cual se somete a luz ultravioleta, por varias horas (6-12 h). Posteriormente, el fraguado se continua en una estufa a $40^{\circ} \mathrm{C}$, por algunas horas.

Para la segunda variante (deshidratación en alcoholes), la preparación se sumerge en la mezcla de resina en las mismas proporciones a la indicada anteriormente. Previo a 


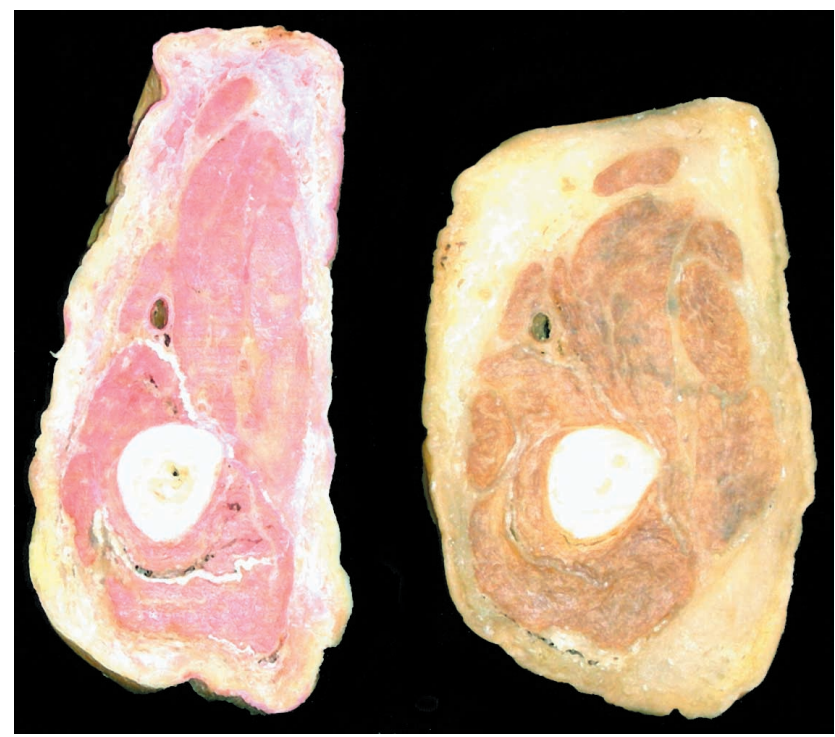

Fig 1. Secciones transversales de muslo, plastinadas con silicona. La preparación del lado izquierdo fue teñida con una solución al $1 \%$ de AC10, cuando estaba en acetona al $80 \%$.

\section{RESULTADOS}

La utilización de silicona que se trabaja a temperatura ambiente, nos ha permitido maximizar el proceso de producción de plastinados en nuestro Departamento de Anatomía. De hecho, en los tres años de funcionamiento del Laboratorio de plastinación, hemos realizado 300 plastinados en silicona y 85 en resina poliéster. Todos estas preparaciones han sido incorporadas a la docencia de los cursos de pregrado de Anatomía y Neuroanatomía para Medicina, de Anatomía para Enfermería y a los cursos de postítulo para los Becados de Neurología y Neurocirugía, de Radiología, de Anestesiología y de Otorrinolaringología. Esto ha significado que, además de las disecciones tradicionales, los alumnos tienen un número significativamente mayor de preparados anatómicos disponibles en los pasos prácticos; situación muy apreciada por los estudiantes, lo que queda expresado abiertamente en las encuestas de evaluación de los cursos indicados, aplicadas por el Centro de Educación Médica y la Vicerrectoría Académica.

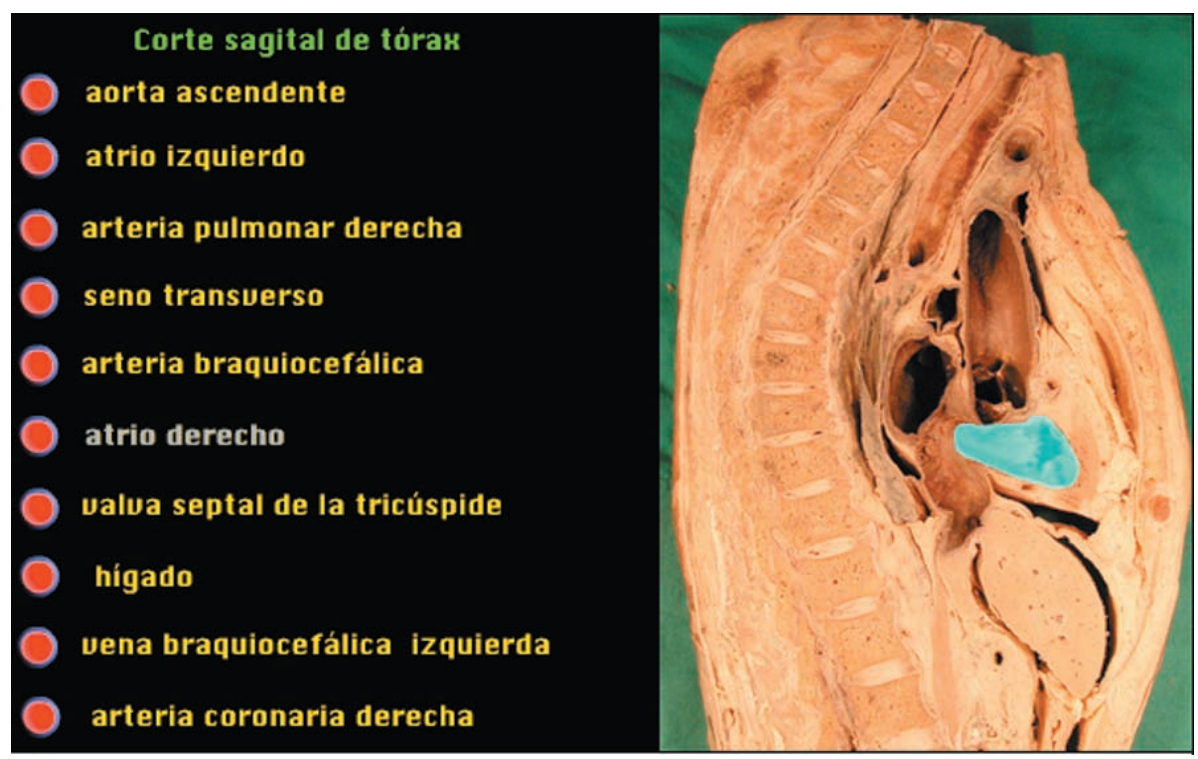

Como una ayuda adicional para los estudiantes, un variado número de plastinados han sido fotografiados y esas imágenes digitales han sido animadas con el software Flash de Macromedia, para crear verdaderos módulos de auto intrucción, que hemos demostrado con estudios estadísticos son de gran utilidad en el aprendizaje de los alumnos (Inzunza \& Bravo 2002). Algunas de estas animaciones han sido incorporadas en las páginas web de nuestro Departamento de Anatomía. (Figs. 2, 3, 4 y 5).

Fig 2 Corte parasagital de tórax, plastinado con silicona. La imagen de este preparado fue animada con el software flash, para facilitar su estudio.

esto, se le han extraído todas las burbujas de aire que contenga la mezcla y la pieza anatómica se introduce en la resina muy lentamente para no producir nuevas burbujas de aire. Una vez sumergida, se lleva directamente a la aplicación de luz ultravioleta, tal como se indicó previamente. En este caso, se obtiene una pieza que ha sido incluida en resina, sin que se haya realizado impregnación forzada. A la fecha tenemos piezas preparadas de esta manera que ya tienen dos años y que se mantienen en óptimas condiciones de transparencia de la resina y de preservación de la pieza anatómica. (Figs. 4 y 5$)$.
http://escuela.med.puc.cl/paginas/Departamentos/Anatomia/ PaginasWeb/Portada.html

http://escuela.med.puc.cl/paginas/cursos/primero/ NEUROANATOMIA/Cursoenlinea/MAIN.HTML 


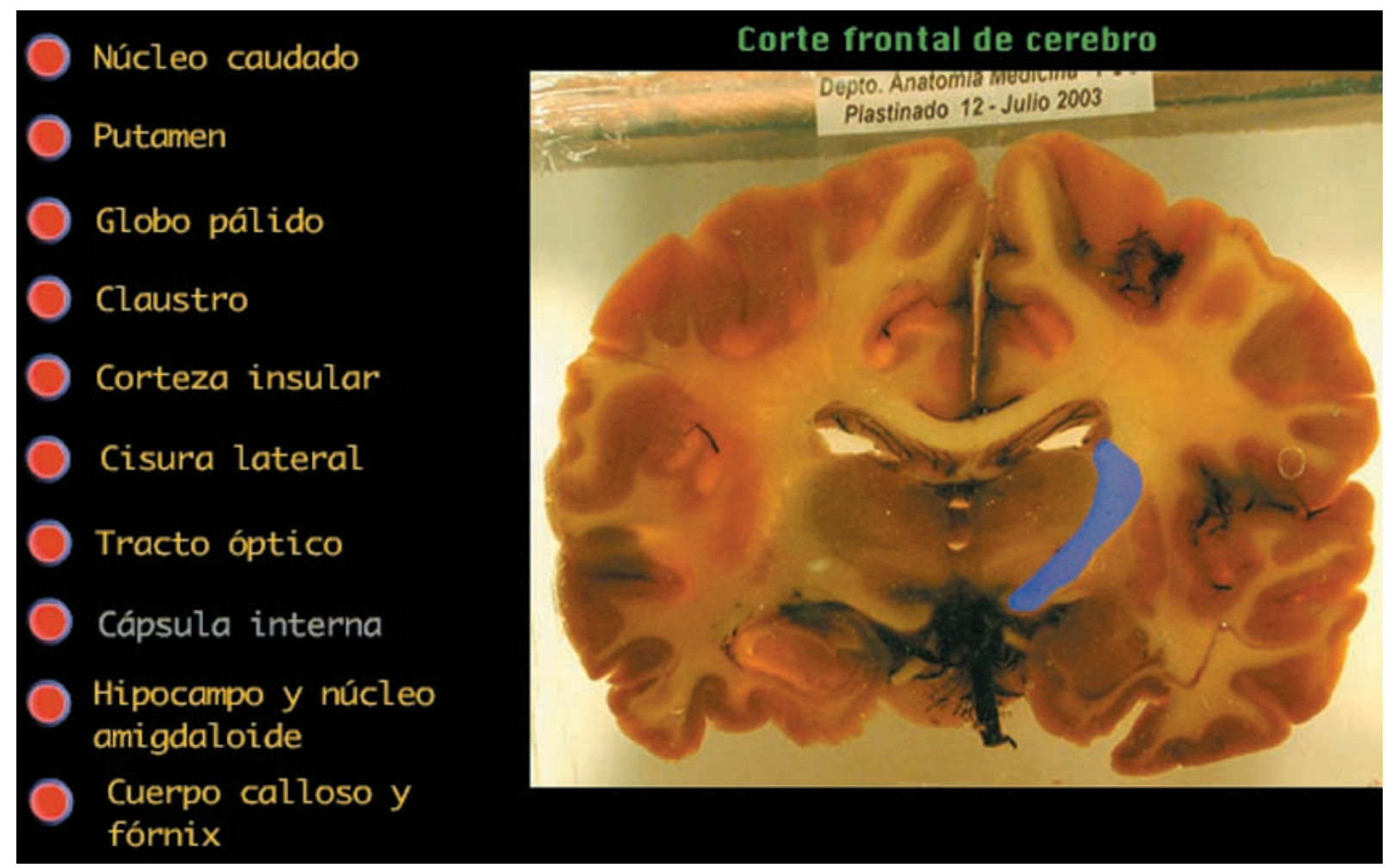

Fig 3. Corte frontal de cerebro plastinado con resina poliéster, utilizando deshidratación con acetonas e impregnación forzada en vacío. La imagen de este preparado también fue animada utilizando flash.

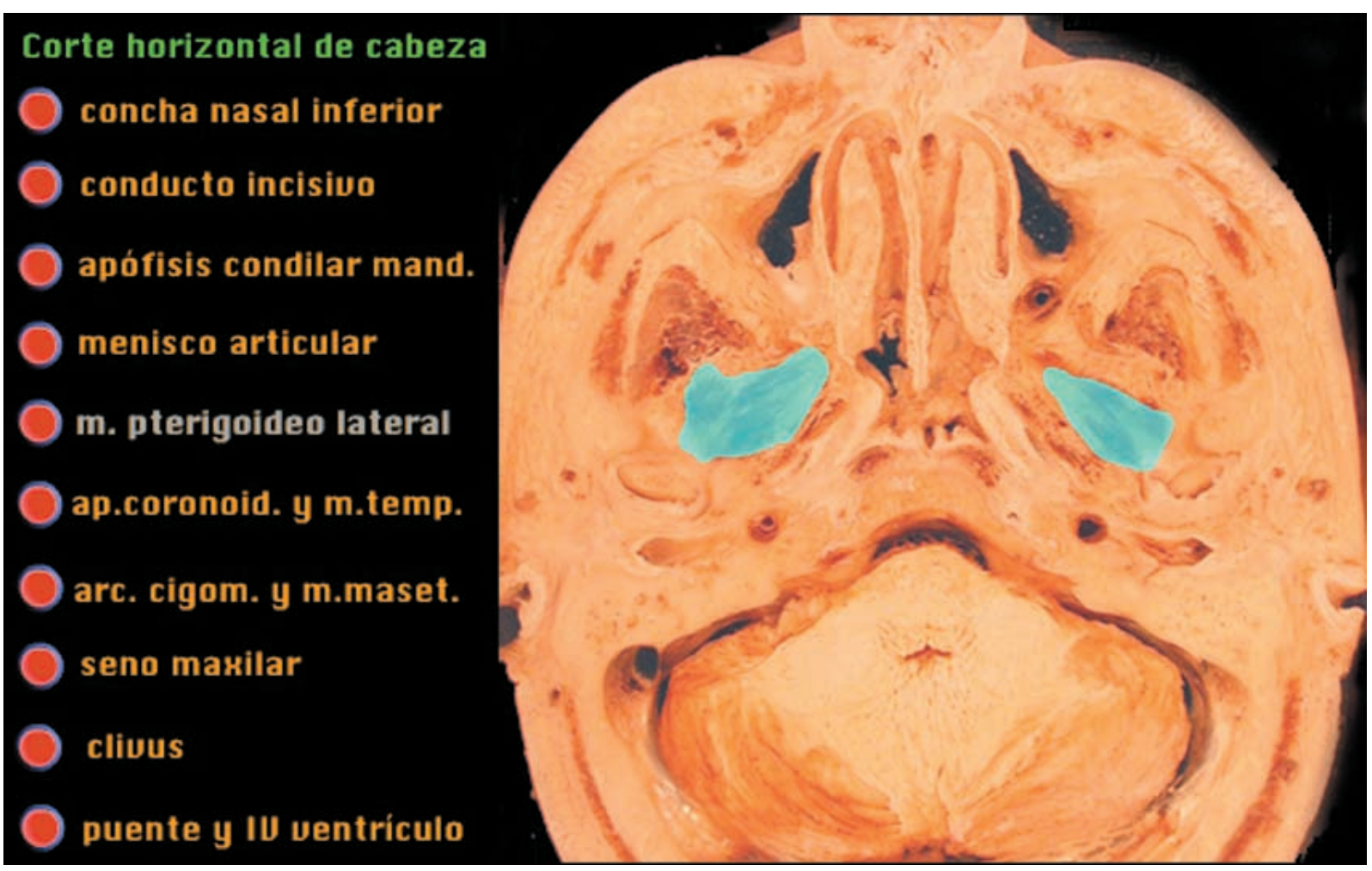

Fig 4. Corte horizontal de cabeza incluida en resina poliéster utilizando deshidratación en alcoholes. En este caso no hay impregnación forzada. 

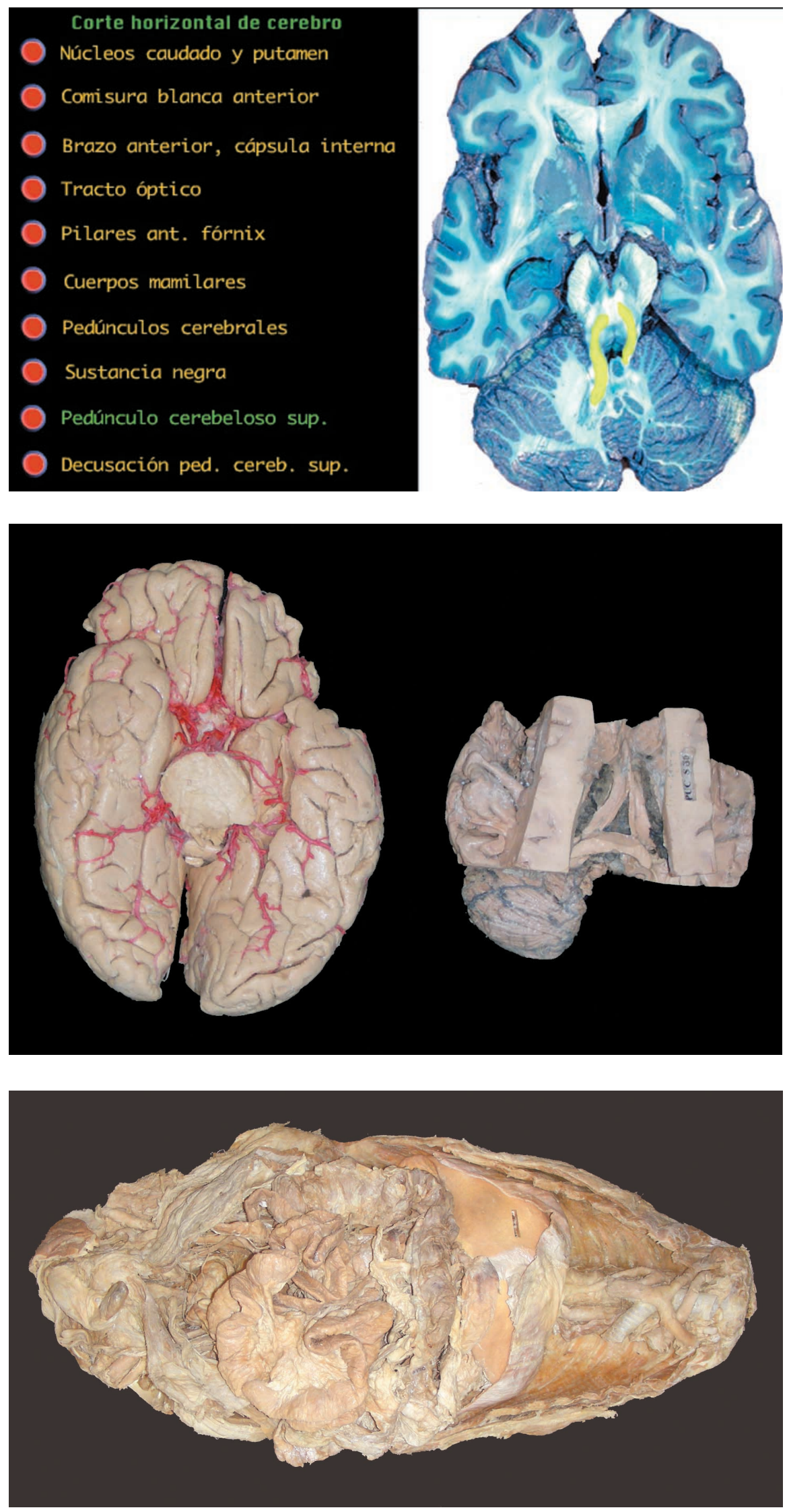

Fig. 5 Corte horizontal de cerebro teñido con la técnica de Barnard, Roberts y Brown y, posteriormente, incluido en resina poliéster (deshidratación en alcoholes). La fotografía digital previa a la inclusión, fue animada con flash.

Fig. 6. Plastinados en silicona de preparaciones de cerebro. La foto de la izquierda muestra vasos arteriales que fueron inyectados con latex coloreado., previo a la fijación del tejido.

Fig. 7. Plastinado en silicona de una disección de tronco que permite ver cavidades torácica y abdominal con algunos órganos in situ. 


\section{DISCUSIÓN}

Si bien es cierto que el término plastinación, utilizado por von Hagens para el proceso de impregnación de polímeros en órganos, y preparaciones cadavéricas, es relativamente reciente, el uso en microscopía electrónica de impregnación de tejidos con resinas epóxicas para lograr cortes ultra finos, es bastante antiguo (Pease \& Baker 1951). Por lo tanto, von Hagens tomó este conocimiento existente y lo aplicó a piezas anatómica grandes, incluso a cuerpos completos, utilizando, además, nuevos compuestos desarrollados por la industria, como es el caso de la silicona. La silicona utiliza tres componentes, el polímero silicona, el crosslinker y el catalizador. En la técnica de von Hagens, se mezcla el polímero con el catalizador, por lo tanto, esta mezcla debe mantenerse a $-20^{\circ} \mathrm{C}$ para evitar su endurecimiento. En el caso de la técnica con siliconas de Dow Corning, comercilizadas por Corcoran Laboratories, lo que se mezcla es el polímero con el crosslinker, por lo tanto, esta mezcla puede trabajarse a temperatura ambiente ya que no endurece. Para que esta mezcla pueda polimerizar se debe aplicar el catalizador, como se indica en material y método. Esta diferencia en la técnica que, pareciera de poca importancia, en la práctica significa que, al no tener que mantener la cámara de vacío en el interior de un freezer, no se interrumpe el proceso de deshidratación en acetona de las piezas anatómicas; proceso que obligatoriamente debe realizarse a $-20^{\circ} \mathrm{C}$, y que es la etapa más consumidora de tiempo de toda la técnica de plastinación.
Además, trabajar a temperatura ambiente, permite, alternativamente, realizar impregnaciones forzadas de resinas poliéster o epóxicas, sin cambios en la disposición de los equipos del laboratorio. Personalmente he descartado el uso de resinas epóxicas, por ser éstas 5 veces más caras que las poliéster, por ser más complicada su manipulación y por no mostrar, en mi experiencia, ventajas significativas como aquellas descritas en la literatura, por ejemplo, mayor transparencia.

Una aplicación adicional que hemos encontrado para las resinas poliéster, es la posibilidad de proteger preparados frágiles, como es el caso de los vaciados en acrílicos de vasos sanguíneos realizados en diversos órganos. Estos preparados se emplean como modelos para estudiar la vascularización de los órganos. En estos casos se emplea la variante de inclusión en resina poliéster, evitando el deterioro progresivo debido a las fracturas de las ramas más finas de estos modelos.

Por último, el uso combinado de plastinados con imágenes de scanner y resonancias magnéticas de regiones equivalentes del cuerpo humano, ha permitido que nuestros estudiantes de Medicina se familiaricen tempranamente con imágenes de Anatomía Clínica que serán de gran utilidad en su formación profesional.

Agradecimientos: Deseo expresar mis agradecimientos al Dr. Oscar Inzunza por sus críticas al presente trabajo, así como a los Srs. José Miguel Massman y Alexis Miranda por su colaboración técnica.

BRAVO, H. Plastination and additional tool to teach anatomy. Int. J. Morphol., 24(3):475-480, 2006.

SUMMARY: In our Department of Anatomy at the school of Medicine, we have introduced a plastination laboratory with the purpose of better preservation of the cadaveric material. In the impregnation of the specimens we use silicone polimer which is handle at room temperature. This way we get the best producción of plastinated material either in silicone or polyester resin. During the last tree years we have plastinated 300 pieces in silicone and 85 pieces in polyester resin. All of these material have been used to teach Anatomy and Neuroanatomy to medical students, nurses, and residents in Neurology, Radiology, Anesthesia, and Otorinolaryngology. Besides the traditional dissection, the studens have an important number of anatomical preparations for their human body anatomical learning.

KEY WORDS: Plastination; Silicone; Polyester resin.

\section{REFERENCIAS BIBLIOGRÁFICAS}

Barnard, J.W.; Roberts, J. O. \& Brown J.C. A simple macroscopic staining and mounting procedure for wet section from cadaver brains. Anat. Rec., 105:1-17, 1949.

Bravo, H. \& Inzunza, O. Evaluación de algunos programas computacionales en la enseñanza de la anatomía y neuroanatomía de la Facultad de Medicina de la Pontificia Universidad Católica de Chile. Rev. Chil. Anat., 13(1):79-86, 1995.

Inzunza, O. \& Bravo, H. Impacto de dos programas computacionales de anatomía humana en el rendimiento del conocimiento práctico de los alumnos. Rev. Chil. Anat. 17(2):205-9, 1999.

Inzunza, O. \& Bravo, H. Animación computacional de fotografías, un real aporte al aprendizaje práctico de anatomía humana. Rev. Chil. Anat., 20:151-7, 2002.
Pease, D. C. \& Baker, R. F. Electrón Microscopy of nervous tissue. Anat. Rec., 110:505-29, 1951.

von Hagens, G.; Tiedemann, K. \& Kriz W. The current potencial of plastination. Anat. Embryol., 175: 411-21, 1987.

Dirección para correspondencia:

Prof. Dr. Hermes Bravo

Departamento de Anatomía

Escuela de Medicina

Pontificia Universidad Católica de Chile

Casilla114-D

Santiago - CHILE

Email: h6ravo@med.puc.cl

Recibido : 16-06-2006

Aceptado: 17-07-2006 